
Safety on 23/09/19, available online: https://www.tandfonline.com/doi/full/10.1080/14773996.2019.1667095 


\title{
WHY COPIED OR TRANSPOSED SAFETY, HEALTH AND WELL-BEING LEGISLATION ARE IMPRACTICABLE AND IRRELEVANT IN DEVELOPING ECONOMIES
}

\author{
Nnedinma Umeokafor \\ Kingston University, London, United Kingdom \\ Email:nnedinmaik@hotmail.com
}

\begin{abstract}
This study examines why some adopted, copied or transposed health, safety and well-being (HSW) legislation, standards and measures (LSMs) from developed countries are impracticable and irrelevant in developing and emerging countries (DECs). This stems from the little or no attention that this area has received. The critical review and analysis of relevant literature and selected HSW legislation and regulatory approaches shows that there are no enabling environments for some of the adopted or copied LSMs which are not compatible with the contexts of Nigeria. Most of them are developed based on pre-existing and functional environments, which are lacking in the DECs of which one is the adequate level of HSW awareness. The study also shows that the pre-requisite parties for the effective implementation of the LSMs are lacking in a lot of instances. This is exacerbated by one of the main barriers - the regulatory approach and rules, for example the goal-based regulation which is the foundation of the adopted LSMs. While the individual efforts in relation to the copying and adoption of the LSMs are applauded, the implications of the cultural and technology differences are evident. Typically, in developed contexts, construction operations are mainly mechanised but are labour-intensive in DECs. While context-based LSMs are recommended, they should be informed by adequate research. Although a stepping-stone in exploring the topic, the study offers insight into the implications of non-context based LSMs in DECs but empirical studies are recommended.
\end{abstract}

Keywords: Adopted Health and Safety legislation, Environment, Health and Safety Laws, Modify, Nigeria

\section{BACKGROUND AND RATIONALE OF RESEARCH}

The poor health, safety and well-being (HSW) record and practices of many industries such as construction are extensively reported in literature (for example see: Agbede et al. (2016) for Nigeria; Health and Safety Executive (HSE) (2018) for Britain; Muiruri and Mulinge (2014) for Kenya; Alkilani et al. (2013) for Jordan; and Kheni (2008) for Ghana). On a visit to South Africa, Waterson (2019:1) witnessed that none of the workers '...repairing ... overhead electricity lines used safety harnesses or other forms of personal protective equipment'. This is consistent with the experiences of the author of the current paper on various visits to Nigeria. Statistically, according to the incident data in Nigeria from 2014 to September 2016, 238 fatalities and 3361 injuries were reported across all the industries or which the construction industry accounted for 1358 (39.24 per cent), the highest account the industries (International Labour Organisation (ILO) 2016). This is indicative because accidents are highly underreported in Nigeria (ILO 2016), just as in many developing and emerging countries (DECs).

Extant literature establishes that one of the explanations to this is HSW standards, legislation and their regulatory systems (Alkilani et al. 2013; Finneran and Gibb 2013; Kheni 2008; Muiruri and Mulinge 2014; Umeokafor 2017). Finneran and Gibb (2013) show that regulation 
and compliance with health and safety (H\&S) laws are fundamental for HSW improvement. In other words, other HSW improvement measures such as design for safety (DFS) (Gambatese et al. 2018), integrating occupational health and safety (OHS) in the decisions of organisations, employees training programmes, attention to cultural and motivation issues (Pybus 1996) are dependent on robust HSW legislation, effective regulatory system and compliance with H\&S legislation. For example, the Construction Design and Management (CDM) regulations 2015 stipulate duties for clients, designers and contractors which include that designers should, where possible, design out hazards and that clients should ensure that relevant information is provided to relevant duty holders including designers and contractors. Such information enable the designers to design out hazards. This shows the significant driving and legal role of regulations such as the CDM 2015 (where they are in existence) in DFS. Of course, this does not mean that compliance is guaranteed, but at least, the likelihood of compliance may be higher and the legal ground for enforcement is established. DFS has been found to significantly contribute to improving HSW as it eliminates or reduces the hazards (Gambatese et al. 2018), higher in the risk control hierarchy.

Although HSW management, legal and regulatory framework in countries such as Britain have limitations, for example, the 'so far as is reasonably practicable' quantification in H\&S legislation pose challenges for small firms in terms of interpretation (Lofstedt 2011), they are established and developed and are (arguably) more efficient when compared to many countries. They even go above the European Union standards in some cases (Lofstedt 2011). This may explain the better HSW records in Britain (Eurostat 2015 in HSE 2018) where it has maintained the lowest standardised fatal injury rates even among other large economies.

Conversely, the poor enforcement and compliance with HSW legislation are reported in many so-called DECs (for example, Alkilani et al. 2013 for Jordan; Umeokafor et al. 2014 for Nigeria; Muiruri and Mulinge 2014 for Kenya; Kheni 2008 for Ghana). Also, consistent with all these countries, as with most other DECs, is that most of the legislation and regulatory systems originated from developed countries (DCs) (Idoro 2008; Umeokafor et al. 2018). Many LSMs are also adopted from developed countries (Dabup 2012; Danso et al 2015 Umeokafor et al. 2018) because there are no existing or adequate ones in DECs (Dabup 2012; Idoro 2008). For example, in Nigeria, Personal Protective Equipment (PPE) Regulations 2002 are adopted because there is no local ones that covers PPE (Idoro 2008). Idoro (2011a) and Umeokafor (2017) go on to cover other regulations adopted from the Britain of which the updated versions are not limited to CDM Regulations 2015, Manual Handling Operations Regulations 1992 as amended in 2002, Provisions \& Use of Work Equipment (PUWER) Regulations 1998.

However, Kheni (2008), Umeokafor and Windapo (2016) and Umeokafor et al. (2018) and Danso et al. (2015) make a case against the copying or transposing of H\&S practices from DCs to DECs contexts such as Ghana and Nigeria. Danso et al. (2015) argue that such practices '.. have to be carefully developed or adapted in a joined-up way through research, such that they map unto the project lifecycle (the context of the DECs) to provide a coherent and a unified framework that offers guidance for dealing with the H\&S issues...'. With country specific-studies, well-informed and workable practical solutions and recommendations will be enabled (Ulubeyli et al. 2014). The same argument can be made in terms of HSW LSMs.

Furthermore, there are concerns on how LSMs are adopted or copied and their effectiveness. For example, Aniekwu (2017), Dabup (2012) and Idoro (2011a) demonstrate that most of the adopted H\&S legislation and policies are unenforceable by the local H\&S regulators, impracticable and irrelevant. Using CDM Regulations 2015 as an example, Umeokafor et al. (2018) show that in Nigeria, when the legislation is adopted, contractors and designers are unable to carry out some of the duties as stipulated in the legislation because it is dependent on the client fulfilling their duties. In DECs such as Nigeria where this is unenforceable, the 
client is not obliged to comply. Umeokafor (2017) found that although the adaption and implementation of these H\&S standards and legislation are applauded, especially where this is voluntary and above mandatory standards or requirements, they are counterproductive in some cases because of reasons such as the difference in the regulatory environments. Further, the contexts of DECs receive little attention in the adoption and implementation of these LSMs (Dabup 2012, Kheni 2008 Umeokafor and Windapo 2016). Obviously, this contributes to the poor H\&S record of DECs.

While there is a dearth of HSW literature in DECs (ILO 2016; Umeokafor 2017; Waterson 2019), the extant ones have not examined, in detail, why adopted or copied or transposed HSW legislation, standards and measures from developed contexts are impracticable and irrelevant in DECs. Only a few authors such as Aniekwu (2017), Dabup (2012) and Danso et al. (2015) have mentioned this. The current study fills this gap through a critical review and analysis of literature, legislation and regulatory approaches. Because of internal validity and Nigeria being the largest economy and most populated country in Africa (Abubakar 2015), it is used as a case study. The objectives are to:

- Critically analyse the goal-based and rule-based regulatory approaches toward indicating the most compatible with the Nigerian context.

- Critically review relevant selected HSW regulations from Britain, for example the CDM Regulations 2015 and PUWER 1998, and their application in Nigeria towards unearthing how and why they limit or can limit HSW.

While this is a stepping-stone in exploring the topic, this paper contributes to addressing the dearth of HSW literature in DECs. Emphatically, the thesis of this paper should not be misconstrued as being that the adopted or copied LSMs are without benefits of which are reported in Idoro (2011a\&b) and Umeokafor (2017). Rather, these benefits are outside the scope of this paper, to be covered in another paper.

\section{SELECTED HSW REGULATORY FRAMEWORKS}

\section{International labour standards}

'International labour standards (ILS)...serve as targets for harmonising national law and practice in a particular field...' (ILO 2019). This can happen through many ways. Firstly, countries examine and revise their legislation and policies to comply with the instrument they intend to ratify but ratify the ILO convention while implementing the revised legislation and policies. Secondly, some countries decide not to ratify an ILO convention but use ILS as the model for drafting their policies and law (ILO 2019). Thirdly, some countries ratify the convention and then bring their national laws and policies inline (ILO 2019).

Just like many DECs, while Nigeria has ratified the Occupational Safety and Health Convention, 1981 NO 155 in 1994, unlike some countries where it will be automatically applicable at national level (ILO 2019; Okene 2009), it is not the case because its legal system is dualist (Okene 2009). By implication, the Occupational Safety and Health Convention, 1981 NO 155 does '.. not have the force of law in Nigeria until such instruments are specifically incorporated into Nigerian law (through legislative process)' (Okene 2009: 30). While ILO (2016) reports that this convention alongside its other OHS conventions that Nigeria ratified - Convention 032 (Protection against Accidents (Dockers)), 1932 and Convention 019 (Equality of Treatment (Accident Compensation), 1925 - are in force in Nigeria as at 2016, the section below shows that they are yet to achieve the desired outcome.

\section{Regulation of HSW in Nigeria}

In response to the ratified ILO Convention 155 on Occupational Safety, Health and Working Environment, the National Policy on Occupational Safety and Health came into force in 2006 (ILO 2016). There is the Nuclear Safety and Radiation Protection Act of 1995 (functional in 
2001) which established the Nigerian Nuclear Regulatory Authority (NNRA) whose responsibility is to oversee nuclear safety and radiation protection. The Factories Act CAP F1, L.FN. 2004 is the local HSW legislation that covers factories in Nigeria (Federal Republic of Nigeria 2004a). The Federal Ministry of Labour and Employment Inspectorate Division (FMLEID) oversees the Act including its enforcement (Federal Republic of Nigeria 2004a). Also, the National Industrial Court Act of 2006 established the National Industrial Court of Nigeria (NICN), which handles matters related to the Factories Act 2004.

Authors such as Abubakar (2015), Dabup (2012), Idoro (2011a) rightly described the HSW regulatory regime and legislation in Nigeria as inadequate, fragmented and dysfunctional. The Factories Act CAP F1, L.FN. 2004 is riddled with limitation. For example, fines are as low as 1000 Naira (£2), display screen equipment is not covered in the Act (Umeokafor et al. 2018), Further, Article 87 of the Act implies that construction activities and sites are not covered by the Act. Hence the regulation of HSW in the industry is complex including being selfregulated in many ways (Umeokafor 2017). For instance, contractors adopt and implement HSW legislation from developed countries (Idoro 2011a) and local Building Code which were yet to receive legislative backing (Omeife and Windapo (2013). Also, the Council for Regulation of Engineering regulates and controls engineering practices and training, and monitor construction processes including building structure safety and investigating building collapse, as enabled by the Engineers (Registration etc.) Act, CAP E11 2004 (Federal Republic of Nigeria 2004b). Dabup (2012) assert that 'some laws relative to H\&S are embedded within the country's environmental laws' (Dabup 2012: 37). The fragmentation with multiple parties and obviously different standards, interests has significant negative implications including counter-productivity (Umeokafor 2017). There is the need for a holistic and contemporary national occupational safety and health (OSH) Act (ILO 2016).

Furthermore, the enforcement of the HSW by relevant authorities is poor (Dabup 2012; Diugwu et al. 2012; Umeokafor 2017). While the inspectors from FMLEID are empowered by law, in practice the case is different. There is evidence of insecurity of inspectors (Okojie 2010), limited enforcement because of the lengthy courts system (Idubor and Osiamoje 2013) and cost-intensive enforcement (Umeokafor 2017). According to ILO (2016), there is the lack of enough person power and logistical capacity for enforcement; there is no national approved OSH Code of Practice; the extant HSW legislation do not cover all the workplaces and the function of some institutions overlap with no statutory backing.

\section{METHODOLOGY}

A critical review, analysis and discussion of relevant literature, selected pieces of legislation and regulatory approaches were adopted. The iterative literature review process and steps explained in Templier and Pare (2015) was adopted. These steps are:

- Formulating the research question and objective(s);

- Searching the extant literature;

- Screening for inclusion;

- Assessing the quality of the primary studies;

- Extracting and analysing data (Templier \& Pare 2015; Pare \& Kitsiou 2016).

Formulating the research question and objective(s), searching the extant literature and screening for inclusion

The formulation of research questions and objectives are already covered in the preceding sections. In terms of searching for extant literature, according to Pare et al. (2015) and Pare and Kitsiou (2016), this can be selective or representative, the primary source conceptual and empirical in nature but rarely involve a comprehensive search. In the current study, the search was selective and the primary sources conceptual and empirical. The aim was to find legislation or standards that were adopted from DCs but were impracticable in DECs and any 
relevant supporting literature. Consequently, 16 pieces of legislation that relate to Britain adopted by contractors in Nigeria (Idoro 2011a) were screened for inclusion and the updated versions of two were selected, namely CDM Regulations 2015 and PUWER 1998. The listed legislation in Idoro (2011a) are not limited to: 'Construction Design and Management Regulations (2007), Control of Substances Hazardous to Health Act (1998), Construction (Head Protective) Regulations (1989), Construction (Lifting Operations) Regulations (1961), Construction (General Provisions) Regulations (1961), Construction (Working Place) Regulations (1996), Provisions \& Use of Work Equipment Regulations (1992), Safety Representatives and Committees Regulations (1977), Noise at Work Regulations (1989) and Construction (Health \& Welfare) Regulations (1966)'. Importantly, companies outside the construction industries may also adopt the non-construction related legislation above.

CDM regulations 2015 and PUWER 1998 were selected because: it is unrealistic and impracticable to review all the pieces of legislation applicable hence the two are used as examples or a starting point; both are applicable to the construction industry of many DECsthe most hazardous industry in many countries; both influenced the legislation or regulatory framework of some DECs; both are used in Britain (one of the countries if not mainly the country) from where most LSMs in DECs originated; among many; PUWER also include absolute regulations and applicable to not only the construction industry; of internal validity.

The rest of the selective searches concentrated on literature that would be central and pivotal to the topic (Pare and Kitsiou 2016). For example, an extensive systematic review (name withheld for review purposes) shows a publication output of 6 papers in construction H\&S regulations and standards in Nigeria over a 36-year period. This search was complemented by the citation approach - searching the reference lists of papers included the six above and books relevant to the topic for 'leads' to articles that can be used (Umeokafor et al. 2018). The author has preconceptions of a few relevant literature that was reviewed.

\section{Assessing the quality of the primary studies}

While Pare et al. (2015) and Pare and Kitsiou (2016) argue that in critical reviews 'No formal quality or risk of bias assessment of included primary studies is required' or essential, most of the papers used in the current paper were peer-reviewed. While this does not guarantee optimum level of quality, it shows that the materials have undergone rigorous assessment by the scientific committee and arguably reliable to some extent (Umeokafor 2017).

\section{Extracting and analysing data}

According to Pare et al. (2015) and Pare and Kitsiou (2016), a variety of analysis methods can be adopted in critical reviews. For the current research, the analysis commenced by the exploration of the author's preconceptions and extensive experiences on the topic under the broad parent themes:

1) The irrelevance and impracticality of some copied or transposed HSW LSMs from developed countries in DECs.

2) Why adopted, copied or transposed HSW LSMs from developed contexts are impracticable and irrelevant in DECs.

Based on this, the author created a synthesis matrix (Ramdhani et al. 2014) of own preconceptions and extensive experiences, all were relevant to the study. The author then read through the relevant literature and the selected legislation and populated the matrix accordingly to address the research question or parent themes. Simultaneously, the synthesis matrix was expanded with new ideas and concepts, which were further explored and developed. In some cases, this resulted in searching for relevant literature to support or refute the discourse. These resulted in the themes and subthemes below which were also discussed and further critically analysed. 


\section{THE IRRELEVANCE AND IMPRACTICALITY OF COPIED OR TRANSPOSED HSW LSMS FROM DEVELOPED COUNTRIES IN DECS: AN OVERVIEW}

Following on from the outline of how the adopted CDM Regulations 2015 is impracticable in Nigeria in the introduction, the regulations require commercial client to ensure that any principal contractor or contractor appointed prepares a construction phase plan before any works. While contractors in Nigeria may have H\&S plans, in practice, the position of a principal contractor (PC) who will work in accordance with the CDM requirements are limited to some projects. Because CDM regulations are not enforceable in DECs such as Nigeria the appointment of principal designers (PD) by clients is not obligatory. Consequently, the PD is not obliged to carry out their CDM regulations duties, which would have enabled the PC to effectively carry out their duties. One of such duties is that the PD should work with the PC, update them on any risks that should be controlled during the construction. While it can be argued that the main contractor can always do this, the question is whether they will have the enabling environment if the client does not comply with their duties under the CDM. Of course, the size of the client, project and contractors determines this in that large contractors in Nigeria are able to get clients to adhere to their standards (Umeokafor 2017); in this case, the implementation of the CDM regulations in possible. However, constitutes a little fraction of the construction contractors, as small and medium scale contractors who are mostly indigenous contractor, make up about $78 \%$ of the contractors in Nigeria and the rest are foreign and indigenous owned (cf. Aniekwu 1995).

Under regulations 8 of the CDM Regulations, part of the general duties include that designers (including PD) appointed to a project must have the skills, knowledge and experience. It goes on to state that the contractors or designers that accept these jobs must fulfil the requirements above if they must take on the designer or contracting roles. These are crucial in the adequate implementation of the CDM and the expected outcomes. The rationale for this competency requirement is to ensure that people or organisations in these positions have the capacity to work effectively. To this effect, HSE (2015) provides guidance on sensible and proportionate enquiries in terms of organisational capability to comply with the CDM regulations. These enquiries include carrying out prequalification checks on potential tenderers' experiences and $\mathrm{H} \& \mathrm{~S}$ records in managing risks; checking their membership of professional bodies or institutions; and asking them standard H\&S questions in PAS 91: 2013 (Publicly Available Specification) Construction related procurement. While prequalification check of potential tenderers in public projects is a legal requirement (Aje 2012) and checking their membership of professional bodies or international certification occurs in Nigeria in selected projects (Umeokafor 2017), the quality of these is questionable (Aje and Oke 2012). For example, Aje and Oke (2012) demonstrate that the H\&S criteria in pre-qualification checks are not thorough, robust and receive little attention. Specifically, in their study, they found that of the 14 prequalification check factors such as technical information about business, evidence of business registration, tax and VAT clearance, H\&S has the second to the lowest mean score of 3.12 and ranks $13^{\text {th }}$ to the clients in order of relevance; while to consultants it ranks $12^{\text {th }}$ in order of relevance with a mean score of 3.34, to contractors it has a mean score of 4.07 and ranks 3rd in order of relevance. The p-value shows that the respondents are not in agreement in ranking the factors, suggesting that the emphasis or importance attached to this by the clients, contractor and consultants vary hence the need for a universal prequalification document (Aje and Oke 2012) and steps to improve the level of importance attached to H\&S. In agreement with Hatush and Skitmore (1996), Aje and Oke (2012) go on to demonstrate that the safety criteria in prequalification checks are subjectively assessed, not taken seriously by the clients and rarely would contractors be rejected on safety grounds. The point is that without $H \& S$ being thorough, robust and taken seriously during pre-qualification checks, the effectiveness, practicality and workability of CDM Regulations in this regard is limited. 


\section{WHY COPIED OR TRANSPOSED HSW LSMS FROM DEVELOPED CONTEXTS ARE IRRELEVANT AND IMPRACTICABLE IN DECS}

\section{Differences in technological levels and construction methodology}

The differences among countries remain an explanation for the discourse. Danso et al. (2015) argue that differences between the countries of origin of the copied H\&S practices and the country in which they are to be implemented have hampered adopted or copied HSW practices. One example is the level of technological differences between the contexts of these countries. Specifically, '... whereas construction operations are highly mechanised in the developed contexts, in DCs such as Ghana (Nigeria and Kenya), construction operations are highly labour intensive hence the degree of exposure of labour to H\&S hazards ... is far greater' (Danso et al. 2015:77). Construction methodologies, for example, mixing and pouring of concrete, which in DCs will likely be mechanised, are likely to be done manually in many DECs except on large projects. While manuals methods of construction in DECs such as Nigeria is rapidly declining, giving way for mechanised methods (Idoro 2011b), a study of Nigerian construction workers in 2006 by Idoro (2011b) reveals a significant correlation between rates of accidents and injuries per worker and mechanisation. Of course, mechanisation itself does not cause incidents; rather, according to Aksorn and Hadikusumo's (2007) finding on the Thai construction industry, they are caused by improper speeds, exceeding the prescribed speed limits, or unsafe speed actions, using defective equipment and tools to work, among many, incorrect use of tools, equipment and machinery. This is supported by Idoro (2011b) supports in terms of Nigeria.

\section{Procurement of materials and supply chain issues}

Following on from the preceding paragraph, in DECs such as Nigeria, the use of secondhand plant and equipment is commonplace (Idoro 2011b). These secondhand plant and equipment are, mainly, imported from DCs. Many come with no service history, are broken down or some key parts that will offer vital information such as the loading or lifting capacity of the equipment may be missing or in another language (Umeokafor 2017). Most times the skills needed to repair or operate the plant and equipment are lacking in DECs (Umeokafor 2017) hence some requirements of PUWER are farfetched. For example, PUWER (1998) stipulates duties for persons and organisations that operate, own and/or control work equipment and on businesses or organisations whose employees use work equipment. This is whether they own it or not. By implication, employers who use work equipment, equipment-hire companies and owner of work equipment have responsibilities. They are to ensure that it is suitable for intended use, safe for use, maintained and inspected, among many, only trained persons use the work equipment and adequate information must have been provided.

In terms of the supply chain, plant and equipment hire companies may not comply with their duties under PUWER because they are not obliged to comply in DECs. Hence, when contractors or clients want to comply they lack the necessary information or environment that encourage compliance. Importantly, the Factories Act L.F.N 2000 covers work equipment including the supply chain and sale, but as noted earlier, it is not applicable to the construction industry.

\section{Differences in the structure or organisation of the construction team}

Umeokafor (2018) argues that the differences in social and political contexts account for the non-transferability of research findings and recommendations of many studies from developed economies. The same arguments can be made for adopted or copied HSW regulations and the differences in the structure or organisation of the construction team. For example, in Britain, the change from the CDM Regulations 2007 to 2015 means that the Construction Design Management Coordinator (CDM-C) was replaced with a new role, PD. The PD's responsibility is to co-ordinate H\&S during the pre-construction stage of construction. In other words, they have to ensure that the client is aware of their duties, 
among many, design, plan and monitor the pre-construction stage, including ensuring that foreseeable risks are identified, eliminated and controlled. This is a legal requirement; hence, every construction project where there is more than one designer, a PD should be appointed by the client as early as possible. This is not enforceable in many DECs such as Nigeria. In Nigeria, the use of the PD is not usually in the project team and even when the designers want to do this, the client is not obliged by law to work with them. The implications of this include that the duties of the PD may not be carried out in accordance with the CDM 2015. This would also likely impact on the responsibilities of the clients and contractors and even the facilities management team. For example, H\&S file should be prepared by the PD and revised as the project progresses; this file is then held by the client and can be used by the facilities management team for maintaining and managing the building. When the PD does not prepare and update the $H \& S$ file, the implications of this is obvious. It can be argued that without the $\mathrm{PD}$, the H\&S file may still be prepared. Of course, it may be prepared but the questions are who is legally accountable for this? To what extent will the H\&S file be fit for purpose? Will the clients who are supported to provide the PD with relevant information or an existing H\&S file do this? The likely responses to these is no or 'to their discretion'. Of course, being a legal obligation does not guarantee quality but contributes to this and enables enforcement.

\section{HSW regulatory framework}

Equally important is the HSW regulatory framework, which is pivotal to the regulation and implementation of the adopted or copied LSMs. Abubakar (2016) observes that the OSH regulatory framework of the many so-called DCs such as Britain is consolidated occupational safety and health (COSH) while that of many so-called DECs is distributed occupational safety and health (DOSH). The author goes on to assert that "DOSH regulatory framework leverages on multiple and less coherent legal provisions dispersed in various related laws ... (while) the $\mathrm{COSH}$ regulatory framework refers to a relatively harmonised regulatory and enforcement framework which comes with mandate expansion, enrichment of regulations, increased regulator powers, more budgetary allocations as well as enhanced executive and financial independence' (Abubakar 2016: 61-62). By implication, HSW LSMs and Approved Codes of Practices in the COSH regulatory framework countries are unlikely to function effectively in the DOSH regulatory environment such as Nigeria where the construction industry may be worse as the HSW regulatory framework is complex (Umeokafor 2017).

\section{Difference in workforce-inspector ratio}

The LSMs in DCs are developed to meet the adequate workforce-inspector ratio (Abubakar 2015). However, when LSMs are copied or adopted from DCs into DECs where the workforce-inspection ratio is inadequate, those dependent or influenced by enforcement are are likely to be ineffective. Based on ILO guideline, Abubakar (2015) establishes that the recommended number of FMLEID inspectors for Nigeria with a workforce of about 55 million in 2014 is between 1300 and 5,500. However, according to Akpan (2013) there were a little over 200 around 2013 and ILO (2016) claims that in 2016, the total number of staff in the department was 267. However, as at 31st of March 2014, the UK HSE has 3081 staff including 1396 inspectors (Abubakar 2015).

\section{Incompatible regulatory approaches and nature of rules}

Regulatory frameworks are designed to be compactable with specific types of legislation or rules and guidance documents and based on the country-contexts. The H\&S regulatory system of Britain is based on goal-setting approach (GBR) for achieving compliance (Fairman and Yapp 2005), a contrast of rules-based or prescriptive regulatory approaches (RBR). However, in practice, pure versions of either GBR or RBR are rarely implemented rather there is usually a combination of the elements of one or the other (Decker 2018; Hale et al. 2015). According to Decker (2018) and Penny et al (2001), the GBR specify outcomes, goals, standards or principles but do not specify how to achieve compliance hence makes room for various ways of achieving compliance. Conversely, RBR specifies the mandatory 
ways to achieve compliance (Fairman and Yapp 2005; Penny et al 2001), the rules are precisely drafted, high particularistic, provides limited or no exceptions (Decker 2018) and rigid.

This means that GBR rules are flexible, as the regulated can decide how to achieve the regulatory objectives (Decker 2018). It encourages innovation, enables the regulated to take responsibility for their actions, more adequate for the dynamic nature of the society (Penny et al 2001) and reduces the burden on the regulator. Conversely, its understanding and interpretation depends on the knowledge and experience of the regulated but regulator can (Hale et al. 2015). This may increase the compliance.

In contrast, the implications of the RBR are not limited to being precise hence the regulated is aware of what to do to achieve compliance (Decker 2018). It is very effective in 'constraining regulatory discretion' hence the regulator is accountable for the outcomes of the regulatory objectives (Decker 2018). Compliance can be measured without waiting for the outcome that the regulations for which it is designed hence the regulated assured of complaince (Hale et al. 2015). The RBR, however, does not support innovation, can be too rigid and may not be adequate in dynamic environments. The burden on the regulator is too much hence inadequate for regulators with limited resources (Umeokafor 2017). Hence, the HSW rules used in these approaches should be consistent and appropriate with the regulatory approach.

The appropriateness and potential effectiveness of GBR and RBR are determined by contextual factors (Decker 2018, Penny et al. 2001). Drawing on the factors below, Decker (2008) opines that GBR is suitable for H\&S because of the diverse nature of the risks therein and it is difficult to apply RBR. While this may be so for Britain, considering the context of Nigeria, is GBR the most adequate? The adopted regulations from Britain are goal-based. Some factors in Decker (2018) are:

First, 'the simplicity or complexity of the setting' - the RBR is likely to be appropriate for simple settings where the regulated is homogenous but the GBR appropriate for more complex environments where the regulated is heterogeneous. Contextually, the Nigerian construction industry is heterogeneous and the setting is complex. If this is the case, it is tempting to conclude that GBR will be adequate for industries such as construction.

Second, 'the characteristics, capabilities and attitude of the regulated community' - a high level of trust between the regulated and the regulators is needed for GBR to thrive because of its structure (Decker 2018). This is unlikely to be effective in Nigeria as there is evidence that the regulated and the regulator do not have a good relationship. For example, Okojie (2010) and Umeokafor (2017) report that the regulator of H\&S in factories is attacked while carrying out a site inspection. The regulated opines that the HSW regulator is biased, with false intentions (Umeokafor 2017). These include that the regulator is likely to view the regulated as a money-making avenue because, as seen in Idubor and Oisamoje (2013), the regulated may be willing to bribe them in HSW matters.

Further on this factor, GBR is hard to apply hence less effective where there are many small and medium enterprise (SME) because they lack the capacity, skills and resources (cf. Fairman and Yapp 2005). Consequently and because of other findings in Fairman and Yapp (2005), they recommend RBR for SMEs in terms of H\&S. This is in agreement with the happening in Nigeria where SMEs lack the skills, resources and knowledge to comply hence would prefer more guidance or perspective rules (Umeokafor 2017).

Another point under this factor builds on behavioural psychology and economics on which Decker (2018) concludes that the regulated in the GBR approach is likely to be noncomplaint than the regulated in the RBR approach. Studies, for example, Diugwu et al. (2012) already report the low level of compliance with H\&S legislation in Nigeria. There 
are many explanations for this including the uncontextualised LSMs (Aniekwu 1995), low level of HSW law enforcement and obsolete LSMs (Diugwu et al. 2012). If Decker (2018) position holds, then it is illogical to recommend GBR for Nigeria. However, considering the poor safety culture in Nigeria, the dominant 'tick-box mentality' and the higher likelihood of compliance if punishments are used (Umeokafor 2017), it is tempting to conclude that RBR is highly needed.

Third, GBR is supportive and responsive to innovation. Given the dynamic nature of the society and significant changes in the market, GBR would be appropriate but subject to qualifications and caveats while RBR is appropriate where the setting is the contrast (Decker 2018). If this is the case, considering industries such as construction (which is gradually following the fast pace of development), GBR may be appropriate.

Based on the points covered so far in this subsection, the verdict of the most appropriate regulatory approach between GBR and RBR is inconclusive. Rather, a logical conclusion, which to some extent is supported by empirical evidence in Umeokafor (2017), is that a combination of GBR and RBR or detailed guidance may be appropriate for industries like construction. Over time, RBR rules may be reduced when the safety culture of the country or their attitudes towards HSW have improved.

\section{Differences in culture and OHS maturity level}

Cultural differences including safety culture are also worth discussing. Dabup (2002) opines that multinationals impose policies from their parent companies without considering the local conditions and cultural differences. British OSH culture has evolved to, what Finneran and Gibb (2013) describe as, the innovative stage where there is the emphasis on elimination of risk, among many, integration of OHS in decision-making. In contrast, Nigeria is still in the traditional phase of OHS evolution where there is mainly attention to rules, discipline and enforcement and individual control. The adopted or copied HSW LSMs are developed for OHS contexts in the innovative phase of OHS evolution. Logically, it is likely that when countries such as Nigeria in the traditional phase adopt LSMs designed for innovative phase countries, these LSMs are likely to be impracticable and irrelevant because these countries in the traditional phase are yet to attain the OHS maturity level required for the HSW LSMs to be efficient.

\section{No enabling environment}

So far, it is evident in the discourse that there is no enabling environment for some adopted or copied LSMs their effectiveness in DECs such as Nigeria likely to be low.

\section{No pre-requisite parties for the effective implementation of the copied or adopted LMS}

Most of the adopted pieces of legislation are developed based on pre-existing and functional environments that are lacking in the DECs. For example, the absence of PD, a requirement of CMD 2015 is likely to result in the non-implementation of some parts of the CDM 2015.

\section{Differences in the legal powers of the HSW regulators}

The level of enforcement of HSW legislation and the legal powers of the HSW regulators in the countries of origin of the adopted legislation, which is needed to function effectively, are absent in many DECs such as Nigeria. For example, drawing on the points covered elsewhere in this paper where the HSW inspectors in Nigeria are unable to exercise their powers because of insecurity, weak HSW judicial system and limited inspectors, the contrast is the case in the Britain where the legal system for the HSW regulatory framework and security system is effective. Hence, the inspectors in Britain have a better enabling environment and able to use their powers effectively. Importantly, drawing on the enforcement pyramid, the inspectors in both countries have the similar enforcement process or options- verbal 
advise/warning is the lowest and at the bottom while to prosecution is the highest and at the top of the pyramid (c.f ILO 2016).

\section{The courts system}

Also, in Nigeria while there is dedicated court (the NICN) that handles the Factories Act 2004 matters, there is no such dedicated body in the UK from here the LSMs is adopted (Abubakar 2015). Although this court is unable to enforce the adopted LSMs and NICN is very slow in handling HSW cases (Abubakar 2015), the Nigerian HSW regulatory system is designed to function inline with the process and methods of the NICN.

\section{The level of formality in construction}

The level of formality in DECs is lower than in developed contexts (Wells 2017), making some adopted, copied or transposed LSMs irrelevant or impracticable. The defining factor of informality, according to Wells (2007), is regulation of which one of the four aspects is the regulation of construction workers' terms and conditions of employment. The regulation of construction workers' terms and condition of employment is partially or not carried out in DECs (Wells 2007). This is where a large number of construction workers in DECs are casual workers or self-employed and most of them have no social protection (Wells 2007; Windapo and Jedege 2013). Also, main contractors are not obliged under the adopted or copied HSW legislation to ensure the HSW of subcontractors; they have little concern for the workers (Windapo and Jedege 2013). Understandably, this is because the pieces of transposed, copied or adopted HSW legislation are unenforceable or the local ones are not enforced. If this is the case, then it is logical to conclude that there is no enabling environment for HSW legislation such as the CDM regulations and the international standards such as ISO $45001 \mathrm{emphasis}$ and build on workers involvement and engagement.

\section{CONCLUSION}

Using Nigeria as a case study, this study unearthed why HSW LSMs adopted, copied or transposed from DCs are impracticable and/or irrelevant in DECs. The critical review analysis of relevant literature, selected adopted, copied or transposed HSW LSMs from DCs and regulatory approaches shows that there is no enabling environment for them. It also indicates that most DECs are yet to attain the OHS maturity level required for the adopted or copied HSW LSMs hence they are impracticable and/or irrelevant. Specifically, these pieces of HSW legislation and measures are from countries where the OHS culture are at the innovative OHS evaluation phase and attention is more on the elimination of risks and incorporating OHS in decision making, having gone through various OHS evaluation phases where the attention is on compliance with HSW legislation and individual efforts. Most DECs such as Nigeria are in this latter phase of OHS culture evolution. The review also argues that the regulatory approaches of the adopted HSW legislation and measures are incompatible with the contexts of DECs, one of the main barriers to the practicality and relevance of the adopted HSW legislation. The required parties for the implementation of the adopted measures and legislation are, in some cases, lacking in DCs. There are differences in technology, construction methodologies, level of HSW awareness and cultures, supply chain and procurement of materials and HSW LSM enforcement capacity.

In conclusion, while it is tempting to conclude that the downsides of adopted, copied or transposed LSMs outweighs the benefits, there is no supportive empirical evidence hence illogical and non-scientific. Further research can examine this, as it is outside the aim of this research. However, it is evident that in DECs, LSMs should not be simply copied, transposed or adopted from DCs. LSMs should be context-based, informed by local research, cleverly developed, piloted locally, and, if necessary, subtly implemented to fit into the local context including OHS maturity level, technology, available resources and skills — a recommendation for policy-makers and companies. Companies should ensure that internal 
polices and standards informed by the local context but meet international expectations. The study suggests many hypotheses of which one is that HSW legislation would be more relevant if they were a combination of goal-based rules and rule-based rules or detailed guidance. While a combination of these two is recommended, an empirical study that will test such as hypotheses can also be carried out. Although Nigeria is the case study, the findings of the research may be used as a framework for country-specific studies. The findings of the research may also be applicable to other DECs as some of them share the same characteristics, for example, DOSH regulatory system.

\section{REFERENCES}

Abubakar, U. (2015). An Overview of the Occupational Safety and Health Systems of Nigeria, UK, USA, Australia and China: Nigeria Being the Reference Case Study. American Journal of Educational Research 3(11), 1350-1358

Abubakar, .U. (2016). Structural and implementation issues around the new Nigerian Labour, Safety, Health and Welfare Bill (2012): Lessons From UK, USA, Australia And China. Transactions of the V̌̌B - Technical University of Ostrava, Safety Engineering Series, $11(1), 61-71$.

Akpan, U N (2013). Occupational safety and health systems in Nigeria. A country paper presented at 'the African Regional Labour Administrator (ARLAC) Tripartite Workshop' on strengthening occupational safety and health system for the excluded, Zambia, November 4-8.

Aniekwu, A. (1995). The business environment of the construction industry in Nigeria, Construction Management and Economics, 13 (6), 445-455

Aniekwu, N. (2007). Accidents and safety violations in the Nigerian construction industry, Journal of Science and Technology, 27 (1), 81-89.

Aje, I. (2012). The impact of contractors' prequalification on construction project delivery in Nigeria, Engineering, Construction and Architectural Management 19, 159-172.

Aje, I. O and Oke, A. E (2012). An Evaluation of contractors' prequalification requirements in Nigeria, Journal of the Nigerian Institute of Quantity Surveyors, 1 (1) 9-19

Dabup, N. L. (2012). Health, safety and environmental implications in Nigeria's oil and gas industry. Philosophiae Doctor thesis, Nelson Mandela Metropolitan University, South Africa. $\quad$ Retrieved on $12-02-17$ from http://www.masterbuilders.co.za/resources/docs/OHSPDFs/Final\%20HSE\%20Implications\%20040613\%20in\%20Nigerias\%20Oil\%20and\% 20Gas\%20Industry\%20PhD\%20Constr\%20Man\%20Thesis.pdf

Danso, F. O., Buda, E., Ahadzie, D. K., Nani, G., and Manu, P. (2015). Towards a framework for the management of health and safety and well-being on adaptive-retrofit projects in Ghana, Procs of ARCOM Doctoral Workshop health, safety and wellbeing, University of Edinburgh, UK

Decker, C. (2018). Goals-based and rules-based approaches to regulation. BEIS Research Paper Number 8. May 2018. Department for Business, Energy and Industrial Strategy. Retrieved on 09-12-2018 from

https://assets.publishing.service.gov.uk/government/uploads/system/uploads/attachmen $\mathrm{t}$ data/file/714185/regulation-goals-rules-based-approaches.pdf

Diugwu I.A., Baba D. L., and Egila A. E. (2012). Effective regulation and level of awareness: An expose of the Nigeria's construction industry, Open Journal of Safety Science and Technology, 2012, 2, 140-146.

Fairman, F. and Yapp, C. (2005). Making an impact on SME compliance behaviour: An evaluation of the effect of interventions upon compliance with health and safety legislation in small and medium sized enterprises, Health and Safety Executive (HSE), Research Report 366.

Federal Republic of Nigeria (2004a). Factories Act, CAP F1, LFN 2004, Federal Government Press, Abuja, Nigeria. 
Federal Republic of Nigeria (2004b). Engineers (Registration etc.) Act, CAP E11 2004, Federal Government Press, Abuja, Nigeria

Finneran, A. and Gibb, A. (2013). W099: Safety and Health in construction: Research Roadmap report for consultation. Retrieved on 05-08-2018 from https://dspace.lboro.ac.uk/dspace-jspui/bitstream/2134/12523/3/pub\%20376.pdf

Gambatese, J., Nnaji, C. and Christianson, C (2018). Contracting For Prevention Through Design (PTD): A Case Study. In Saurin, T. A., Costa, D. B., Behm. M., and Emuze, F. (Eds.). Proc:. Joint CIBW99 and TG59 Conference, Salvador, 373-382

Hale, A., Borys, D. and Adams, A. (2015). Safety regulation: Lessons of workplace safety rule management for managing the regulatory burden. Safety Science, 71(B), 112-122

Health and Safety Executive (2015). Managing health and safety in construction: Construction (Design and Management) Regulations 2015, Guidance on Regulations. Retrieved on 12-12- 2018 from http://www.hse.gov.uk/pubns/priced/1153.pdf

Health and Safety Executive (2018). Health and safety at work: Summary of statistics for Great Britain 2018. Retrieved on 02-12-2018 from http://www.hse.gov.uk/statistics/overall/hssh1617.pdf

Idoro, G. I. (2011a). Comparing occupational health and safety (OHS) management efforts and performance of Nigerian construction contractors, Journal of Construction in Developing Countries, 16 (2), 151-173.

Idoro, G. I. (2011b). Effect of mechanisation on occupational health and safety performance in the Nigerian construction industry, Journal of Construction in Developing Countries, 16 (2), 27-45.

Idubor, E. E., and Oisamoje, M. D. (2013). An exploration of health and safety management issues in Nigeria's efforts to industrialize, European Scientific Journal, 9 (12), 154169.

International Labour Organisation (ILO) (2016). Nigeria Country Profile on Occupational Safety and Health 2016. Retrieved on 09 August 2019 from https://www.ilo.org/wcmsp5/groups/public/---africa/---ro-addis_ababa/---iloabuja/documents/publication/wcms 552748.pdf

ILO (2019). How International Labour Standards are used. Retrieved on 09 August 2019 from https://www.ilo.org/global/standards/introduction-to-international-labourstandards/international-labour-standards-use/lang--en/index.htm

Kheni, N. A. (2008). Impact of health and safety management on safety performance of small and medium-sized construction business in Ghana, Doctoral thesis, Loughborough University, UK. https://dspace.lboro.ac.uk/dspace-jspui/bitstream [22 November 2018].

Löfstedt, R. E (2011). Reclaiming health and safety for all: An independent review of health and safety legislation. Retrieved on 02 Dec 2018 from https://assets.publishing.service.gov.uk/government/uploads/system/uploads/attachmen t data/file/66790/lofstedt-report.pdf

Manual Handling Operations Regulations 1992 as amended in 2002. Available at http://www.legislation.gov.uk/uksi/2002/1144/contents/made. Accessed on May 25 2019

Nuclear Safety and Radiation Protection Act of 1995. Available at https://www.amla.org/masteract/download/1066 Accessed on May 272019

Okene, O. V. C. (2009). Brining rights home: The status of internal legal instruments in Nigerian domestic law. Journal of Law, Practice and Procedure, 1(4), 12 -31

Okojie, O. (2010). System for reporting occupational diseases in Nigeria, African Newsletter on occupational health and safety, 20 (3), 51-53.

Omeife, C. A. and Windapo, O. A. (2013). The impact of national building code on professionalism. Proc.: 43rd Builders Conference/AGM, Abuja, Nigeria, 1-12.

Pare and Kitsiou (2016). Methods for literature review. In: Lau, F. and Kuziemsky, C. (eds) Handbok of e-Health evaluation: An evidence-based approach, University of Victoria, Canada. 
Pare, G. Trudel, M., Jaana, M. and Kitsiou, S. (2015). Sythesizing information systems knowledge: A typology of literature review. Information and Management, 52(2), 183199.

Penny J., Eaton A., Bishop P.G., Bloomfield R.E. (2001), The Practicalities of Goal-Based Safety Regulation. In: Redmill F., Anderson T. (eds) Aspects of Safety Management. Springer, London

Personal Protective Equipment (PPE) Regulations 2002. Available at http://www.legislation.gov.uk/uksi/2002/1144/contents/made Accessed on May 27 2019

Provisions \& Use of Work Equipment (PUWER) Regulations 1998. Available at http://www.legislation.gov.uk/uksi/1998/2306/contents/made. Accessed on May 25 2019

Pybus, R (1996). Safety Management: Strategy and Practice. Oxford: Butterworth Heinemann

Ramdhani, A., Ramdhani, M.A., Amin, A. S.(2014). Writing a Literature Review Research Paper: A step-by-step approach. International Journal of Basic and Applied Science, 3, (01), 47-56

Templier, M., and Pare,G (2015). A framework for guiding and evaluating literature reviews. Communications of Association for Information Systems, 37 (6) 112 - 137.

Ulubeyli, S., Kazaz, A. and Er, B. (2014). Health and safety perception of workers in Turkey: a survey of construction sites, International Journal of Occupational Safety and Ergonomics, 20 (2), 323 - 338

Umeokafor, N. I. (2017), Realities of construction health and safety regulation in Nigeria, Doctoral thesis, University of Greenwich, UK.

Umeokafor, N. I. and Windapo, A. O (2016), A framework for managing contextual influence on health and safety on construction projects. In: Proc. 9th Construction Industry Development Board (CIDB) postgraduate conference, Cape Town, South Africa, 285294.

Umeokafor, N. I. Windapo, A. O. and Manu, P. A. (2018). Country context-based opportunities for improving health and safety. In Saurin, T. A., Costa, D. B., Behm. M., and Emuze, F. (Eds.). Proc:. Joint CIBW99 and TG59 Conference, Salvador, 177-186

Wells (2007). Informality in the construction sector in developing countries, Construction Management and Economics 25 (1), 87-93

Waterson, P. (2019) The ironies of occupational safety and health (OSH), Policy and Practice in Health and Safety, 17:1, 1-2, DOI: 10.1080/14773996.2019.1596626

Windapo, A. O. and Jegede, O. P. (2013). A study of heath, safety and environment (HSE) practices of Nigerian construction companies, The professional Builder, 4 (1), 92-103. 